Check for updates

Cite this: RSC Adv., 2018, 8, 20941

\title{
Visual synchronization of two 3-variable Lotka- Volterra oscillators based on DNA strand displacement
}

\begin{abstract}
Chengye Zou, ${ }^{a}$ Xiaopeng $W^{a} i^{a}$ and Qiang Zhang (D) *ab
DNA strand displacement as a theoretic foundation is helpful in constructing reaction networks and DNA circuits. Research on chemical kinetics is significant to exploit the inherent potential property of biomolecular systems. In this study, we investigated two typical reactions and designed DNA strands with a fluorophore and dark quencher for reaction networks using a 3-variable Lotka-Volterra oscillator system as an example to show the convenience of and superiority for observation of dynamic trajectory using our design, and took advantage of the synchronization reaction module to synchronize two 3variable Lotka-Volterra oscillators. The classical theory of chemical reaction networks can be used to represent biological processes for mathematical modeling. We used this method to simulate the nonlinear kinetics of a 3-variable Lotka-Volterra oscillator system.
\end{abstract}

Received 13th February 2018

Accepted 21st May 2018

DOI: $10.1039 / c 8 \mathrm{ra01393d}$

rsc.li/rsc-advances

by luminous intensity; for polymerization of a hybridization chain reaction, ${ }^{14}$ characterization of the hyperbranched chain reaction can be recognized by fluorescence intensity.

Synchronization is an important dynamical behavior and a general and ubiquitous phenomenon that has been investigated in a variety of fields such as complex networks, chemical reaction networks, ${ }^{16-18}$ secure communication, and genetic regulatory networks. Recently, it was found that synchronization is beneficial to DNA nanotechnology; for example, synchronization is applied in self-assembly, ${ }^{19}$ gene expression ${ }^{20}$ and DNA replication. ${ }^{21}$ Synchronized systems can enjoy common dynamical behavior and isochronous signal transition or transmission. Thus, synchronization has extensive application potential in digital and analog DNA circuits.

As compared to previous studies, we have proposed catalysis, degradation and synchronization reaction modules with a fluorophore and dark quencher, and identified different DNA strands with different colors of fluorophores, where the synchronization reaction module is a new reaction module. Then, we compiled these reaction modules into the 3 -variable Lotka-Volterra oscillator and realized synchronization of two 3variable Lotka-Volterra oscillator systems. From the simulations of these reaction modules, it was demonstrated that the DNA implementation of CRN can imitate the dynamical behavior of an ideal formal reaction, and there is a relationship between the reaction rates of DNA CRNs, intermediate CRNs and ideal formal CRNs.

We used visual DSD software to design the DNA strand and test the feasibility of the chemical reaction with DNA strand displacement, and utilized chemical reaction network (CRN) software to numerically simulate the dynamic behavior of the 3variable Lotka-Volterra oscillator.

${ }^{a}$ School of Computer Science and Engineering, Dalian University of Technology, Dalian 116024, China. E-mail: zhangq@dlut.edu.cn

${ }^{b}$ Key Laboratory of Advanced and Intelligent Computing, Dalian University, Ministry of Education, Dalian 116622, China 


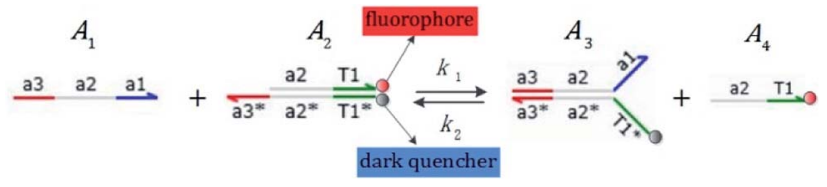

Fig. 1 DNA strand displacement with the fluorophore and quencher. The arrow in a DNA strand indicates the $3^{\prime}$ end. The domain $a_{2}$ is 12 nucleotides, and the toehold domain is usually less than 10 nucleotides, so the toehold binding reaction is reversible.

\section{Recent work}

\subsection{DNA strand displacement with fluorophore and dark quencher}

We presented a reversible, bimolecular chemical reaction, as shown in Fig. 1, where $\mathrm{A}_{1}$ and $\mathrm{A}_{2}$ are reactants and $\mathrm{A}_{3}$ and $\mathrm{A}_{4}$ are products; $k_{1}$ denotes the forward reaction rate, and $k_{2}$ denotes the backward reaction rate. The reaction begins with an invader strand $\mathrm{A}_{1}$ binding to the target strand $\mathrm{A}_{2}$ based on the WatsonCrick model. ${ }^{22}$ The position, number, and length determine the feasibility, reversibility, and reaction rate of DNA strand displacement, respectively. The reaction rate first increases and then decreases with an increase in the length of the toehold, ${ }^{23}$ such that we can adjust the reaction rate by changing the length of the toehold. Reversible and irreversible reactions are 2 types of DNA strand displacement reactions.

The fluorophore and quencher exist at the end of the strand. When the fluorophore and quencher appear in pairs, the fluorophore strand does not fluoresce, but when the fluorophore strand releases from the dark quencher strand, it can be detected by fluorescence intensity.

\subsection{DNA strand displacement with hairpin structure}

Hairpin $^{24-26}$ is a special structure for single strand DNA (ssDNA), which can protect some domains. As shown in Fig. 2, domains $a_{2}, b_{1}$, and $b_{2}$ are protected before the hairpin is open. When an invader DNA strand $\mathrm{X}$ reacts with $\mathrm{H}$, the hairpin is open and then, domains $a_{2}, b_{1}$, and $b_{2}$ can be used for further reactions.

\section{Results}

\subsection{CRN modules}

In DNA strand displacement as a type of chemical reaction, there is a corresponding relationship between DNA CRNs and

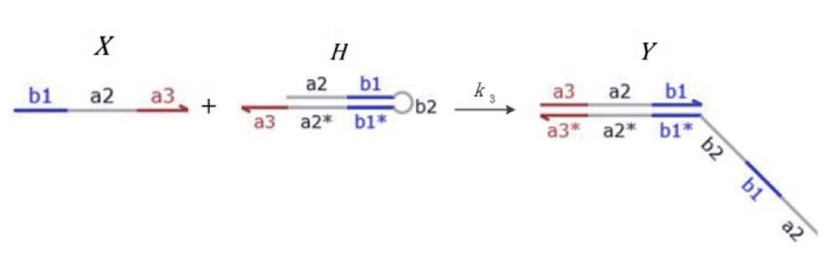

Fig. 2 DNA strand displacement with a hairpin structure. The toehold $b_{1}$ is as long as the other toeholds. The hairpin cannot open spontaneously as a result of the dissociation of $b_{1}-b_{1}^{*}$ hybridization at the end of the branch migration, the loop portion $a_{2}-b_{1}-b_{2}$ of the hairpin is protected if it does not open. the ideal formal CRNs, where there are intermediate CRNs is the transition between DNAs and ideal formal CRNs. In order to endue CRNs modularity, we propose three types of reaction modules by DNA CRNs and ideal CRNs, where $[\mathrm{X}]_{0},\left[\mathrm{X}_{\mathrm{M}}\right]_{0}$ and $\left[\mathrm{X}_{1}\right]_{0}$ represent the initial concentration of species $\mathrm{X}, \mathrm{X}_{\mathrm{M}}$ and $\mathrm{X}_{1}$ in DNA CRNs, intermediate CRNs and ideal CRNs, respectively, and satisfied $[\mathrm{X}]_{0}=\left[\mathrm{X}_{\mathrm{M}}\right]_{0}=\left[\mathrm{X}_{1}\right]_{0} \cdot[\mathrm{Y}]_{0},\left[\mathrm{Y}_{\mathrm{M}}\right]_{0}$ and $\left[\mathrm{Y}_{1}\right]_{0}$ represent the initial concentration of species $\mathrm{Y}, \mathrm{Y}_{\mathrm{M}}$ and $\mathrm{Y}_{1}$ in DNA CRNs, intermediate CRNs and ideal CRNs, respectively, and satisfied $[\mathrm{Y}]_{0}=\left[\mathrm{Y}_{\mathrm{M}}\right]_{0}=\left[\mathrm{Y}_{1}\right]_{0}$.

In the catalysis reaction module (1), as shown in Fig. 3(b), $\mathrm{X}_{\mathrm{M}}^{\prime}$ is produced by $\mathrm{X}_{\mathrm{M}}$ in (5), and the increase in $\mathrm{X}_{\mathrm{M}}^{\prime}$ will catalyze (6), while the producer $\mathrm{X}_{\mathrm{M}}$ can catalyze the production of $\mathrm{X}_{\mathrm{M}}^{\prime}$. According to (1), $\mathrm{d}[\mathrm{X}]_{t} / \mathrm{d} t=-q_{i} C_{m}[\mathrm{X}]_{t}$ and $\mathrm{d}\left[\mathrm{X}_{\mathrm{M}}\right]_{t} / \mathrm{d} t=-\theta_{1}\left[\mathrm{X}_{\mathrm{M}}\right]_{t}$ by (5); if DSD (1) and (2) can approximate to the intermediate (5), $q_{i}=\theta_{1} / C_{m}$ is obtained. According to (3), $\mathrm{d}\left[\mathrm{X}^{\prime}\right]_{t} / \mathrm{d} t=-q_{m^{-}}$ $C_{m}\left[\mathrm{X}^{\prime}\right]_{t}$, while $\mathrm{d}\left[\mathrm{X}_{\mathrm{M}}^{\prime}\right]_{t} / \mathrm{d} t=-\theta_{m}\left[\mathrm{X}_{\mathrm{M}}^{\prime}\right]_{t}$ based on (6). If DSD (3) and (4) can approximate to the intermediate (6), $q_{m}=\theta_{m} / C_{m} . \mathrm{d}[\mathrm{X}]_{t} / \mathrm{d} t$ $=-\theta_{2}[\mathrm{X}]_{t}$ and $\mathrm{d}\left[\mathrm{X}_{\mathrm{M}}\right]_{t} / \mathrm{dt}=-q_{j} \mathrm{C}_{m}\left[\mathrm{X}_{\mathrm{M}}\right]_{t}$, according to (4) and (6); if (4) is equivalent to (6), $q_{j}=\theta_{2} / C_{m}$. Similarly, we can obtain $k_{1}=$ $\theta_{1}$ based on (5), (6) and (7). Initial concentrations of the auxiliary species $\mathrm{A}_{i}^{\prime}, \mathrm{C}_{i}^{\prime}, \mathrm{P}_{j}^{\prime}, \mathrm{Sp}_{j}^{\prime}$ and $\mathrm{Sq}_{j}^{\prime}$ are set to $C_{m}$, where $[\mathrm{X}]_{0} \ll C_{m}$, and $[\mathrm{X}]_{0},[\mathrm{Y}]_{0}$ are the initial concentrations of $\mathrm{X}$ and $\mathrm{Y}$. As shown in Fig. 3(c), the evolutions of $\mathrm{X}$ in DNA CRNs, intermediate CRNs and ideal CRNs are approximately coincident. This shows that DNA CRNs, intermediate CRNs and ideal formal CRNs in the catalysis reaction module (1) are equivalent, but there are nuances between DNA CRNs, intermediate CRNs and ideal formal CRNs.

In catalysis reaction module (2), as shown in Fig. 4(b), $\mathrm{Y}_{\mathrm{M}}^{\prime}$ is produced by $\mathrm{X}_{\mathrm{M}}$ and $\mathrm{Y}_{\mathrm{M}}$ in (13), and the increase in $\mathrm{Y}_{\mathrm{M}}^{\prime}$ will catalyze (14), while the producer $\mathrm{Y}_{\mathrm{M}}$ can catalyze the production of $\mathrm{Y}_{\mathrm{M}}^{\prime}$ and consumption of $\mathrm{X}_{\mathrm{M}}$. According to ref. 1, we have. $q_{i}=$ $\theta_{3}$. Similar to catalysis reaction module (1), $q_{j}=\theta_{4} / C_{m}, q_{m}=\theta_{m} /$ $C_{m}$ and $k_{2}=\theta_{3}$. Initial concentrations of the auxiliary species $\mathrm{A}_{i}$, $\mathrm{B}_{i}, \mathrm{H}_{i}, \mathrm{P}_{j}, \mathrm{Sp}_{j}$, and $\mathrm{Sq}_{j}$ are set to $C_{m}$, where $[\mathrm{X}]_{0},[\mathrm{Y}]_{0} \ll C_{m}$. As shown in Fig. 4(c), the evolutions of $\mathrm{Y}$ in DNA CRNs, intermediate CRNs and ideal CRNs are approximately coincident. This indicates that DNA CRNs, intermediate CRNs and ideal CRNs in catalysis reaction module (2) are equivalent, but there are nuances between DNA CRNs, intermediate CRNs and ideal CRNs.

In the synchronization reaction module, it is assumed that $\mathrm{X}$ and $M a_{i}$ attain instant equilibrium through (18), with $[\mathrm{X}]_{t} /$ $\left[\mathrm{M} a_{i}\right]_{t}=q_{m} / q_{i}$; when $\mathrm{X}_{\mathrm{M}}$ and $\mathrm{M} a_{i}$ attain instant equilibrium through (24), we obtain $\left[\mathrm{X}_{\mathrm{M}}\right]_{t} /\left[M a_{i}\right]_{t}=\theta_{5} / \theta_{m}$. According to (19) and (25), we have $\mathrm{d}\left[M a_{i}\right]_{t} / \mathrm{d} t=-C_{m} q s_{i}\left[M a_{i}\right]_{t}=-\theta_{6}\left[M a_{i}\right]_{t}$; as a result, $q s_{i}=\theta_{6} / C_{m}$. Taking (25) and (28) into account, we obtain $\mathrm{d}\left[\mathrm{Y}_{\mathrm{M}}\right]_{t} / \mathrm{d} t=\theta_{6}\left[M a_{i}\right]_{t}$ and $\mathrm{d}\left[\mathrm{Y}_{\mathrm{I}}\right]_{t} / \mathrm{d} t=k_{4}\left[\mathrm{X}_{\mathrm{I}}\right]_{t}$, respectively; if intermediate reaction (25) can be approximated to the ideal formal reaction (28), $\theta_{6}\left[\mathrm{M} a_{i}\right]_{t}=k_{4}\left[\mathrm{X}_{\mathrm{I}}\right]_{t}$. Because $[\mathrm{X}]_{t} /\left[\mathrm{M} a_{i}\right]_{t}=q_{m} /$ $q_{i}$ when $\mathrm{X}$ and $M a_{i}$ attain instant equilibrium and $\left[\mathrm{X}_{\mathrm{I}}\right]_{t}=$ $[\mathrm{X}]_{t}+\left[M a_{i}\right]_{t}$, we can obtain $k_{4}=q_{i} \theta_{6} /\left(q_{m}+q_{i}\right)=q s_{i} q_{i} C_{m} /\left(q_{m}+q_{i}\right)$. The initial concentrations of the auxiliary species $\mathrm{N} a_{i}, \mathrm{~N} a_{i}^{\prime}, \mathrm{N} b_{i}$, $\mathrm{N} c_{i}, \mathrm{~N} d_{i}, \mathrm{~N} b_{i}^{\prime}, \mathrm{N} e_{i}$, and $N f_{i}$ are set to $C_{m}$, where $[\mathrm{X}]_{0},[\mathrm{Y}]_{0} \ll C_{m}$. Fig. 6(c) shows that $\mathrm{X}$ and $\mathrm{Y}$ can share the same dynamic behavior in DNA CRNs, intermediate CRNs and ideal formal 

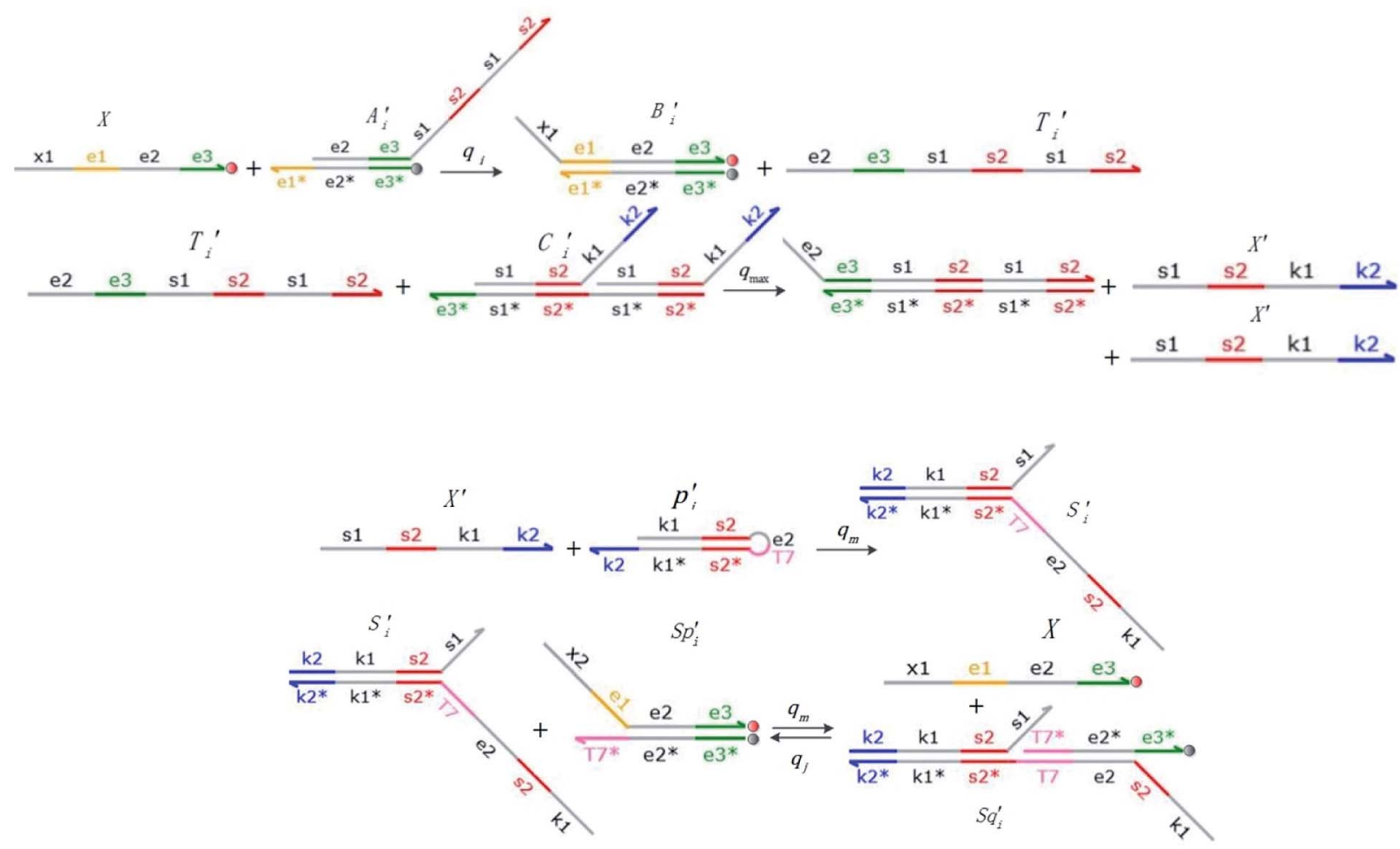

(a)

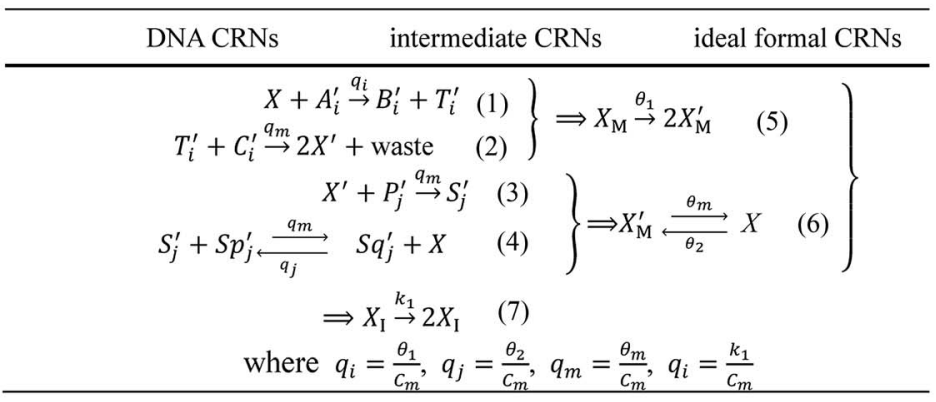

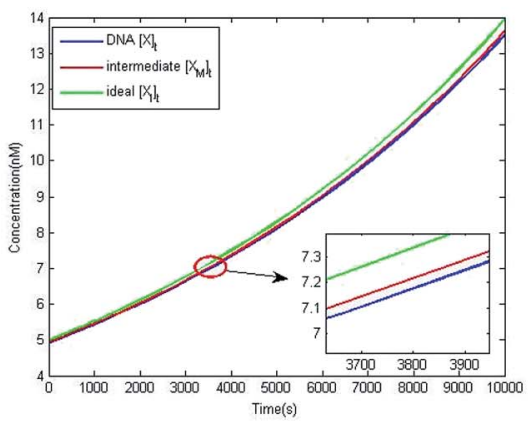

(c)

(b)

Fig. 3 Catalysis reaction module (1) $X \rightarrow$ 2X. DNA reactions are listed in (a); (b) exhibits the DNA CRNs and appropriate ideal CRNs, where intermediate CRNs is the transition between DNAs and ideal formal CRNs; (c) shows the result of the variable X in DNA CRNs, media CRNs and ideal formal CRNs respectively, where $C_{m}=10^{4} \mathrm{nM}$ and $[X]_{0}=\left[X_{M}\right]_{0}=\left[X_{l}\right]_{0}=5 \mathrm{nM} ; q_{i}=10^{-8} \mathrm{nM} \mathrm{s}^{-1}, q_{j}=10^{-7} \mathrm{nM} \mathrm{s}^{-1}$ and $q_{m}=10^{-5} \mathrm{nM} \mathrm{s}{ }^{-1}$. DNA implementation of formal species $X^{\prime}$ is gained by species $X$. Species $X$ reacts with $A_{i}^{\prime}$ to displace $T_{i}^{\prime}$ in (1), $T_{i}^{\prime}$ releases two $X^{\prime}$ in (2). In (3), species $X^{\prime}$ reacts with hairpin $\mathrm{P}_{j}^{\prime}$ to produce $\mathrm{S}_{j}^{\prime}$, and $\mathrm{S}_{j}^{\prime}$ and releases $\mathrm{X}$ in (4) on reaction with $\mathrm{Sp}_{j}^{\prime}$. This reaction replaces the ssDNA strand without the fluorophore to the ssDNA strand with the fluorophore, as adapted from. ${ }^{4} q_{m}$ represents a maximum strand displacement rate constant under the assumption of equal binding strength for all full toeholds; when $q_{i}$ and $k_{i}$ are satisfied $q_{i}, q_{j} \ll q_{m}, k_{i} \ll q_{m} C_{m} ;[X]_{0}$ and $C_{m}$ are satisfied $[X]_{0} \ll C_{m}$, as adapted from. ${ }^{1}$

CRNs, but their synchronous values are different. The reasons for this phenomenon are as follows:

\section{In DNA CRNs}

$$
\begin{aligned}
{[\mathrm{X}]_{0}+[\mathrm{Y}]_{0}=} & {[\mathrm{X}]_{t}+[\mathrm{Y}]_{t}+\left[\mathrm{M} a_{i}\right]_{t}+} \\
& {\left[\mathrm{M} b_{i}\right]_{t}+\left[\mathrm{M} c_{i}\right]_{t}+\left[\mathrm{M} d_{i}\right]_{t} }
\end{aligned}
$$

When DNA CRNs approach reaction equilibrium, the following can be obtained:

$$
\left\{\begin{array}{l}
{[\mathrm{X}]_{t}=[\mathrm{Y}]_{t}} \\
{\left[\mathrm{M} a_{i}\right]_{t}=\left[\mathrm{M} c_{i}\right]_{t}} \\
\frac{\left[\mathrm{M} a_{i}\right]_{t}}{[\mathrm{X}]_{t}}=\frac{q_{i}}{q_{m}}
\end{array}\right.
$$

$$
\left[\mathrm{M} b_{i}\right]_{t}=\left[\mathrm{M} d_{i}\right]_{t} \approx 0
$$

Considering (30) and (31), we can obtain the synchronous value: 

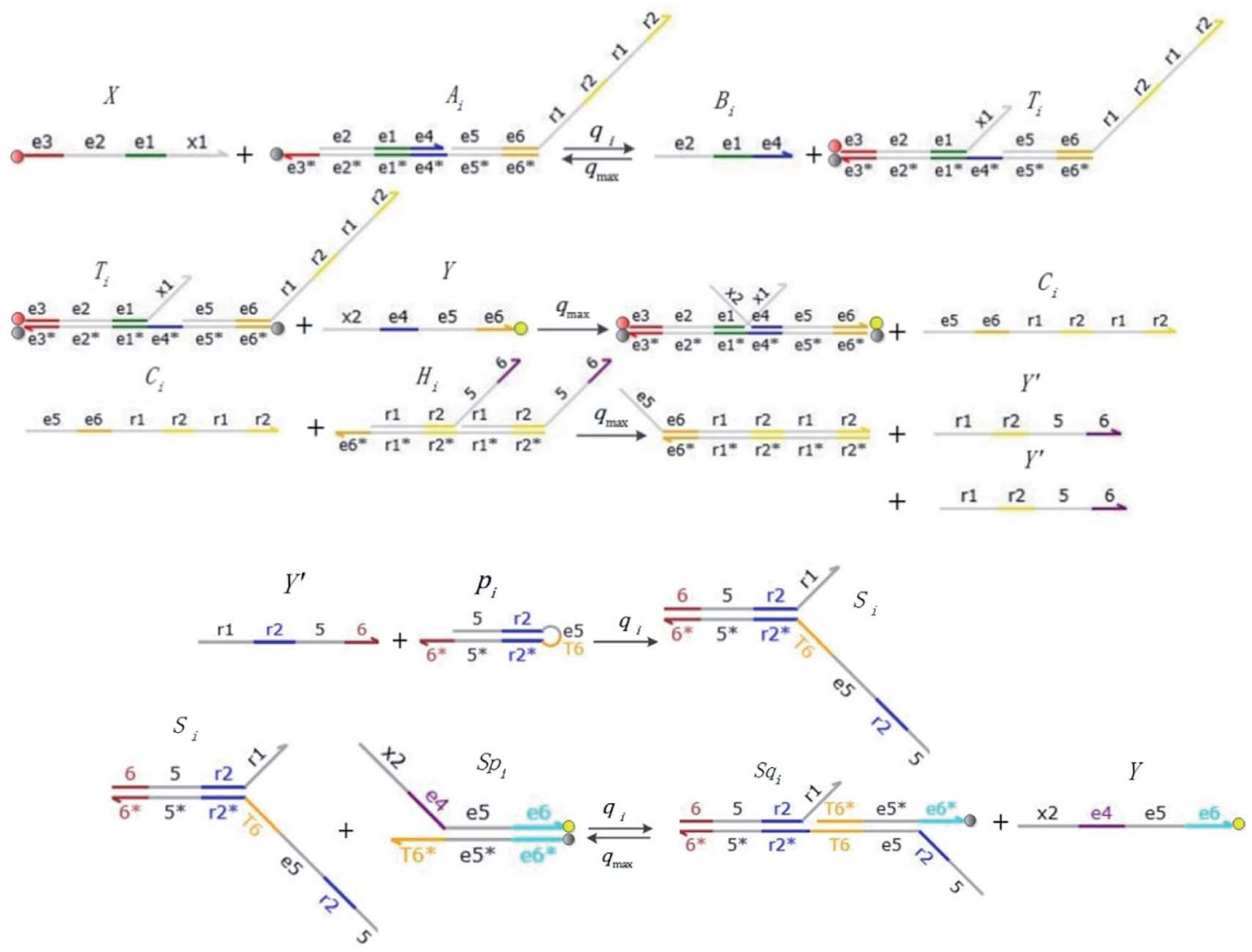

(a)

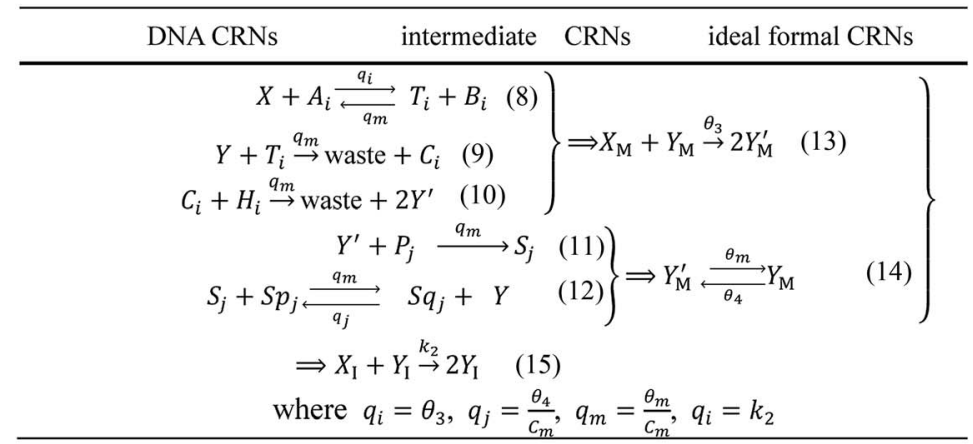

(b)

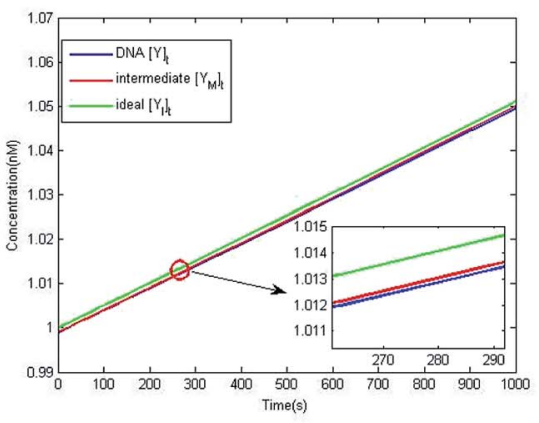

(c)

Fig. 4 Catalysis reaction module (2) $X+Y \rightarrow 2 Y$. DNA reactions are listed in (a) and (b) exhibits the DNA CRNs and corresponding ideal formal CRNs, where intermediate CRNs is the transition between DNAs and ideal CRNs; (c) shows the result of the variable $Y$ in DNA CRNs, media CRNs and ideal formal CRNs, respectively, where $C_{m}=10^{4} \mathrm{nM},[X]_{0}=\left[X_{M}\right]_{0}=\left[X_{l}\right]_{0}=5 \mathrm{nM}$, and $\left[Y_{0}=\left[Y_{M}\right]_{0}=\left[Y_{1}\right]_{0}=1 \mathrm{nM} q_{i}=10^{-5} \mathrm{nM} \mathrm{s}^{-1}, q_{j}=10^{-6} \mathrm{nM}\right.$ $\mathrm{s}^{-1}$ and $q_{m}=10^{-3} \mathrm{nM} \mathrm{s}^{-1}$. DNA implementation of formal species $Y_{M}^{\prime}$ is gained by species $X_{M}$ and $Y_{M}$ in intermediate CRN (13). Species $X$ reacts with $A_{i}$ to displace $T_{i}$. In (9), $C_{i}$ is produced when $Y$ irreversibly displaces $T_{j}$, and $H_{i}$ releases $2 Y^{\prime}$ in reaction (10), as adapted from. ${ }^{1}$ In (11), species $Y^{\prime}$ reacts with hairpin $\mathrm{P}_{j}$ to produce $\mathrm{S}_{j}$, and $\mathrm{S}_{j}$ releases $\mathrm{X}$ in (12) on reacting with $\mathrm{Sp}_{j}$, as adapted from. ${ }^{4}$

$$
[\mathrm{X}]_{t}=[\mathrm{Y}]_{t} \approx \frac{\left([\mathrm{X}]_{0}+[\mathrm{Y}]_{0}\right) q_{m}}{2\left(q_{i}+q_{m}\right)}
$$

\section{In intermediate CRNs}

$$
\left[\mathrm{X}_{\mathrm{M}}\right]_{0}+\left[\mathrm{Y}_{\mathrm{M}}\right]_{0}=\left[\mathrm{X}_{\mathrm{M}}\right]_{t}+\left[\mathrm{Y}_{\mathrm{M}}\right]_{t}+\left[\mathrm{M} a_{i}\right]_{t}+\left[\mathrm{M} c_{i}\right]_{t}
$$

When intermediate CRNs approach reaction equilibrium, we can obtain

$$
\left[\mathrm{X}_{\mathrm{M}}\right]_{t}=\left[\mathrm{Y}_{\mathrm{M}}\right]_{t}=\frac{\left(\left[\mathrm{X}_{\mathrm{M}}\right]_{0}+\left[\mathrm{Y}_{\mathrm{M}}\right]_{0}\right) q_{m}}{2\left(q_{i}+q_{m}\right)}
$$

\section{In ideal CRNs}




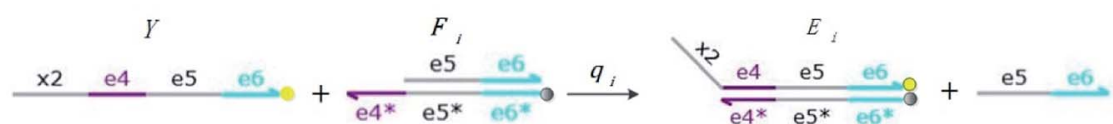

(a)

\begin{tabular}{cc}
\hline DNA CRNs & ideal formal CRNs \\
\hline$Y+F_{i} \stackrel{q_{i}}{\rightarrow} E_{i}, \quad(16)$ & $Y_{\mathrm{I}} \stackrel{k_{3}}{\rightarrow} \emptyset, \quad(17)$ \\
where $q_{i}=k_{5} / C_{\max }$. \\
\hline
\end{tabular}

(b)

Fig. 5 Degradation reaction module $Y \rightarrow \varnothing$ : DNA implementation of formal species $Y$ and degradation with auxiliary species $F_{i}$; in (16), species $Y$ reacts with species $F_{i}$ producing inert waste, where the initial concentration of auxiliary species $F_{i}$ is set to $C_{m}$.

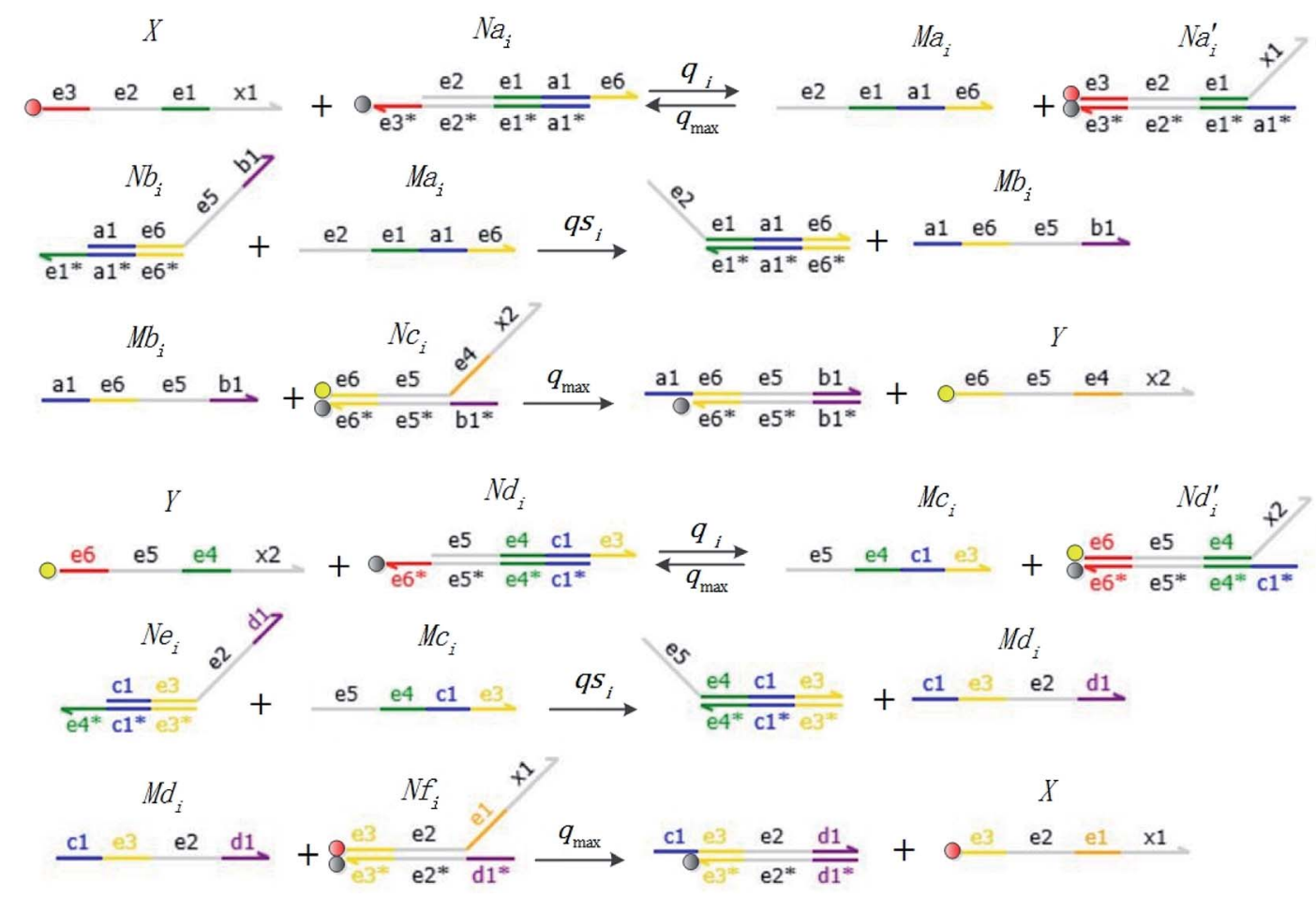

(a)

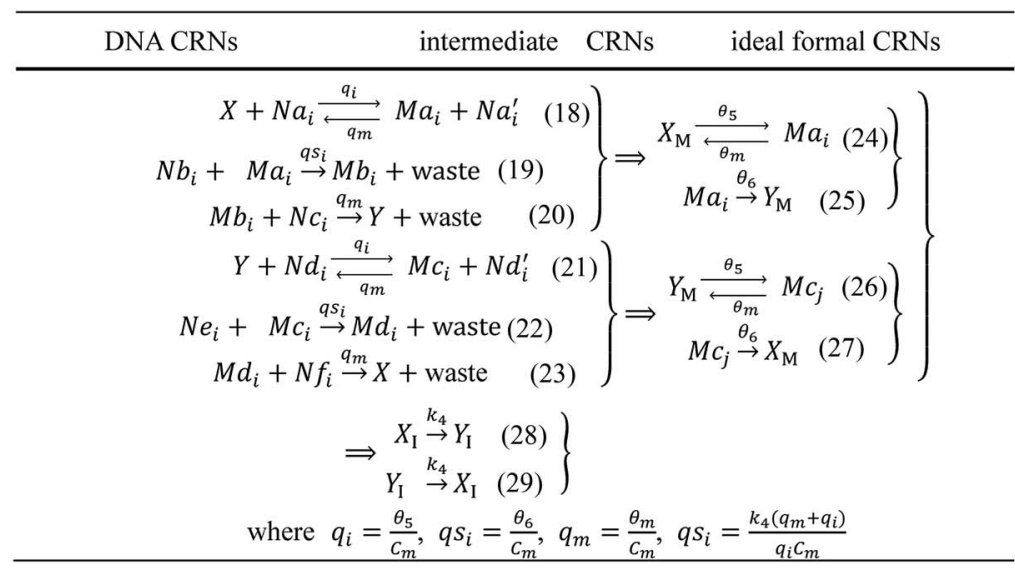

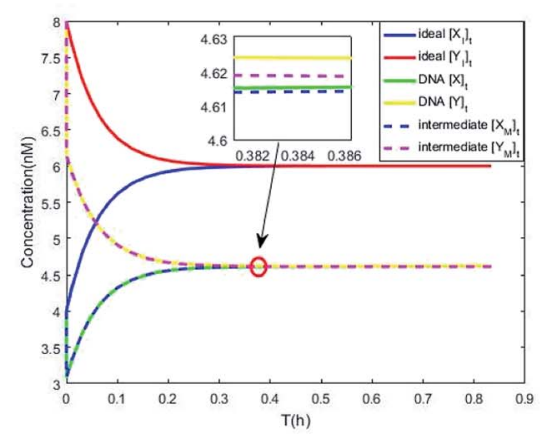

(c)

Fig. 6 Synchronization reaction module. (a) A list of DNA reactions; (b) exhibits the DNA CRNs and appropriate ideal formal CRNs, where intermediate CRNs is the transition between DNAs and ideal formal CRNs; (c) represents the process of synchronization between $X$ and $Y$ in DNA CRNs, intermediate CRNs and ideal formal CRNs, respectively, where $C_{m}=10^{4} \mathrm{nM},\left[\mathrm{X}_{0}=\left[\mathrm{X}_{\mathrm{M}}\right]_{0}=\left[\mathrm{X}_{\mathrm{l}}\right]_{0}=4 \mathrm{nM}\right.$, and $[\mathrm{Y}]_{0}=\left[\mathrm{Y}_{\mathrm{M}}\right]_{0}=\left[\mathrm{Y}_{1}\right]_{0}=8 \mathrm{nM} ; q s_{i}$ $=10^{-6} \mathrm{nM} \mathrm{s}^{-1}, q_{i}=3 \times 10^{-4} \mathrm{nM} \mathrm{s}^{-1}$ and $q_{m}=10^{-3} \mathrm{nM} \mathrm{s}^{-1}$. In (18), $\mathrm{X}$ react with $\mathrm{Na}_{i}$ producing $\mathrm{Ma}_{i}$ reversely; the producer $\mathrm{Ma}_{i}$ reacts with $\mathrm{Nb}_{i}$ to produce $\mathrm{M} b_{i}$ in (19), and $\mathrm{Y}$ is produced by $\mathrm{Mb} b_{i}$ and $\mathrm{N} c_{i}$, which is equivalent to $\mathrm{Y}_{1}$ being produced by $\mathrm{X}_{1}$ in ideal CRNs (28). DSD implementation of ideal reaction (29) is similar to (28). 

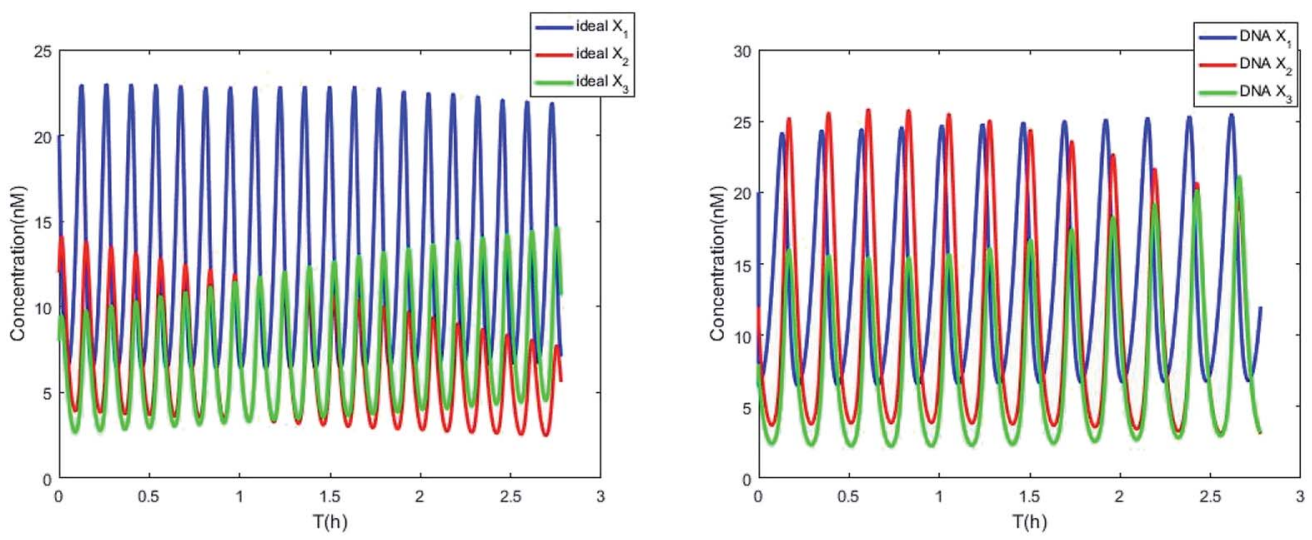

Fig. 7 Evolution of concentrations of $x_{1}, x_{2}, x_{3}, y_{1}, y_{2}$ and $y_{3}$ of two 3-variable Lotka-Volterra oscillator systems based on ideal CRNs and DNA intermediate CRNs, respectively.

$$
\left[\mathrm{X}_{\mathrm{I}}\right]_{0}+\left[\mathrm{Y}_{\mathrm{I}}\right]_{0}=\left[\mathrm{X}_{\mathrm{I}}\right]_{t}+\left[\mathrm{Y}_{\mathrm{I}}\right]_{t}
$$

Eqn (36) is satisfied when $\mathrm{X}_{1}$ and $\mathrm{Y}_{1}$ approach instant equilibrium through (27) and (28)

$$
\left[\mathrm{X}_{\mathrm{I}}\right]_{t}=\left[\mathrm{Y}_{\mathrm{I}}\right]_{t}
$$

Therefore, the synchronous value of $\mathrm{X}_{1}$ and $\mathrm{Y}_{1}$ are obtained as follows:

$$
\left[\mathrm{X}_{\mathrm{I}}\right]_{t}=\left[\mathrm{Y}_{\mathrm{I}}\right]_{t}=\frac{\left[\mathrm{X}_{1}\right]_{0}+\left[\mathrm{Y}_{\mathrm{I}}\right]_{0}}{2}
$$

\subsection{3-Variable Lotka-Volterra oscillator}

The Lotka-Volterra model is one of the earliest sound mathematical principles ${ }^{27-29}$ to describe population dynamics, and the Lotka-Volterra oscillator is known to be an ecological food chain oscillator. A 2-variable Lotka-Volterra oscillator can be described by ideal formal CRNs as follows: ${ }^{1}$

$$
\begin{gathered}
\mathrm{X}_{1} \stackrel{r_{1}}{\longrightarrow} 2 \mathrm{X}_{1} \\
\mathrm{X}_{1}+\mathrm{X}_{2} \stackrel{r_{2}}{\longrightarrow} 2 \mathrm{X}_{2} \\
\mathrm{X}_{2} \stackrel{r_{3}}{\longrightarrow} \phi
\end{gathered}
$$

where $\mathrm{X}_{1}$ and $\mathrm{X}_{2}$ are reactants; $r_{1}, r_{2}$, and $r_{3}$ represent the reaction rate of reaction (39a-c), respectively. Reaction (39a) leads to an increase in $X_{1}$, and $X_{1}$ can catalyze reaction (39a).

The product of $\mathrm{X}_{1}$ will increase the product $\mathrm{X}_{2}$, and $\mathrm{X}_{2}$ can catalyze reaction (39b). When the concentration of $X_{1}$ increases to a certain degree, an increase in $\mathrm{X}_{2}$ will lead to consumption of $\mathrm{X}_{1}$ and the decrease in $\mathrm{X}_{1}$ will slow down reaction (39b), which can lead to a decrease in $\mathrm{X}_{2}$. Therefore, in the cycle, the concentrations of $\mathrm{X}_{1}$ and $\mathrm{X}_{2}$ will fluctuate over time.

According to the basic Lotka-Volterra oscillator, a 3-variable Lotka-Volterra oscillator model can be described by ideal CRNs as follows:

$$
\begin{gathered}
\mathrm{X}_{1} \stackrel{r_{1}}{\longrightarrow} 2 \mathrm{X}_{1} \\
\mathrm{X}_{1}+\mathrm{X}_{2} \stackrel{r_{2}}{\longrightarrow} 2 \mathrm{X}_{2} \\
\mathrm{X}_{1}+\mathrm{X}_{3} \stackrel{r_{3}}{\longrightarrow} 2 \mathrm{X}_{3} \\
\mathrm{X}_{2} \stackrel{r_{4}}{\longrightarrow} \phi \\
\mathrm{X}_{3} \stackrel{r_{5}}{\longrightarrow} \phi
\end{gathered}
$$

CRNs (40) can be represented by the following set of ODEs:

$$
\begin{gathered}
\dot{\mathrm{X}}_{1}=r_{1} \mathrm{X}_{1}-r_{2} \mathrm{X}_{1} \mathrm{X}_{2}-r_{3} \mathrm{X}_{1} \mathrm{X}_{3}=\mathrm{F}_{1}\left(\mathrm{X}_{1}\right) \\
\dot{\mathrm{X}}_{2}=r_{2} \mathrm{X}_{1} \mathrm{X}_{2}-r_{4} \mathrm{X}_{2}=\mathrm{F}_{2}\left(\mathrm{X}_{2}\right) \\
\dot{\mathrm{X}}_{3}=r_{1} \mathrm{X}_{1} \mathrm{X}_{3}-r_{5} \mathrm{X}_{3}=\mathrm{F}_{3}\left(\mathrm{X}_{3}\right)
\end{gathered}
$$

Fig. 8(a) shows the evolution of Lyapunov exponents $\lambda_{i}(i=$ $1,2,3$ ) of ideal formal CRNs (40) with the chemical reaction rate parameter, $r_{1}$. It is known that the kinetic characteristics of the system can be characterized by the Lyapunov exponent, if exist in the range in which one Lyapunov exponent is positive and another Lyapunov exponent is negative, indicating that the system is at a chaotic state. Furthermore $\lambda_{1}<0, \lambda_{2}>0$ and $\lambda_{3}>$ 0 when the parameter is taken as $r_{1}=5.5 / 300 \mathrm{~s}^{-1}$, and the phase map of the state variables $X_{1}, X_{2}$ and $X_{3}$ is shown in Fig. 8(b).

\subsection{Synchronization of two 3-variable Lotka-Volterra oscillator systems}

Considering another 3-variable Lotka-Volterra oscillator system

$$
\begin{gathered}
\mathrm{Y}_{1} \stackrel{r_{1}}{\longrightarrow} 2 \mathrm{Y}_{1} \\
\mathrm{Y}_{1}+\mathrm{Y}_{2} \stackrel{r_{2}}{\longrightarrow} 2 \mathrm{Y}_{2} \\
\mathrm{Y}_{1}+\mathrm{Y}_{3} \stackrel{r_{3}}{\longrightarrow} 2 \mathrm{Y}_{3}
\end{gathered}
$$




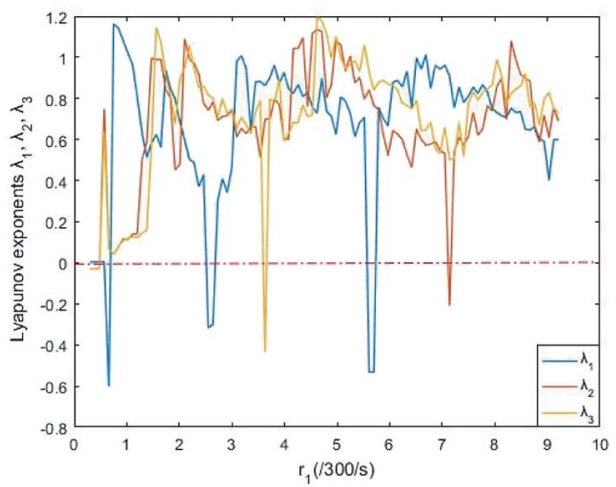

(a)

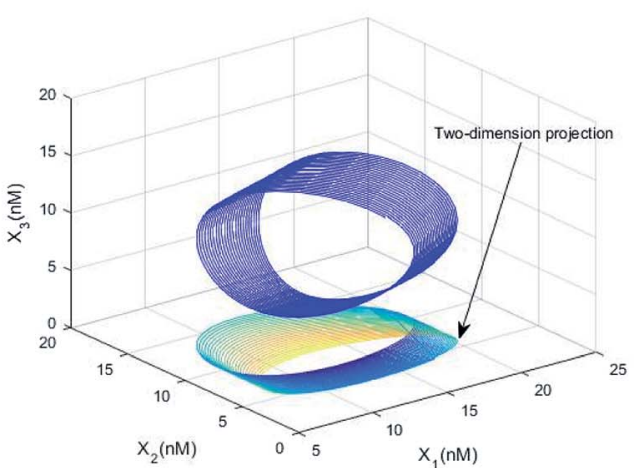

(b)

Fig. 8 (a) The evolution of Lyapunov exponents $\lambda_{i}(i=1,2,3)$ with the chemical reaction rate $k_{1}$. (b) The chaotic attractor in the $\left(X_{1}, X_{2}, X_{3}\right)$ phase space and its two-dimension projection.

$$
\begin{aligned}
& \mathrm{Y}_{2} \stackrel{r_{4}}{\longrightarrow} \phi \\
& \mathrm{Y}_{3} \stackrel{r_{5}}{\longrightarrow} \phi
\end{aligned}
$$

where the initial concentrations of the above two systems are different. In this study, we used four types of fluorophores as reporters: ssDNA $\mathrm{X}_{1}$ and $\mathrm{Y}_{1}$ are identified by the TYE563 fluorophore (blue ball) with $\lambda_{\mathrm{Ex}}=549 \mathrm{~nm}, \lambda_{\mathrm{Em}}=563 \mathrm{~nm}$; $\mathrm{ssDNA} \mathrm{X}_{2}$ and $\mathrm{Y}_{2}$ are identified by the ROX fluorophore (red ball) with $\lambda_{\mathrm{Ex}}$ $=588 \mathrm{~nm}, \lambda_{\mathrm{Em}}=608 \mathrm{~nm}$; ssDNA $\mathrm{X}_{3}$ and $\mathrm{Y}_{3}$ are identified by FAM fluorophore (green ball) with $\lambda_{\mathrm{Ex}}=495 \mathrm{~nm}$ and $\lambda_{\mathrm{Em}}=$ $520 \mathrm{~nm}$; and the dark quencher is Lowa Black RQ. ${ }^{11}$

In order to realize internal synchronization between two chemical reaction networks, we added coupling terms as follows:

$$
\begin{gathered}
\mathrm{X}_{1} \stackrel{r_{1}}{\longrightarrow} 2 \mathrm{X}_{1} \\
\mathrm{X}_{1}+\mathrm{X}_{2} \stackrel{r_{2}}{\longrightarrow} 2 \mathrm{X}_{2} \\
\mathrm{X}_{1}+\mathrm{X}_{3} \stackrel{r_{3}}{\longrightarrow} 2 \mathrm{X}_{3} \\
\mathrm{X}_{2} \stackrel{r_{4}}{\longrightarrow} \phi \\
\mathrm{X}_{3} \stackrel{r_{5}}{\longrightarrow} \phi \\
\mathrm{X}_{1} \stackrel{r_{6}}{\longrightarrow} \mathrm{Y}_{1} \\
\mathrm{X}_{2} \stackrel{r_{6}}{\longrightarrow} \mathrm{Y}_{2} \\
\mathrm{X}_{3} \stackrel{r_{6}}{\longrightarrow} \mathrm{Y}_{3} \\
\mathrm{Y}_{1} \stackrel{r_{1}}{\longrightarrow} 2 \mathrm{Y}_{1} \\
\mathrm{Y}_{1}+\mathrm{Y}_{2} \stackrel{r_{2}}{\longrightarrow} 2 \mathrm{Y}_{2} \\
\mathrm{Y}_{1}+\mathrm{Y}_{3} \stackrel{r_{3}}{\longrightarrow} 2 \mathrm{Y}_{3}
\end{gathered}
$$

$$
\begin{aligned}
& \mathrm{Y}_{2} \stackrel{r_{4}}{\longrightarrow} \phi \\
& \mathrm{Y}_{3} \stackrel{r_{5}}{\longrightarrow} \phi \\
& \mathrm{Y}_{1} \stackrel{r_{6}}{\longrightarrow} \mathrm{X}_{1} \\
& \mathrm{Y}_{2} \stackrel{r_{6}}{\longrightarrow} \mathrm{X}_{2} \\
& \mathrm{Y}_{3} \stackrel{r_{6}}{\longrightarrow} \mathrm{X}_{3}
\end{aligned}
$$

ODEs of CRNs (45) and (46) can be described as follows:

$$
\begin{aligned}
\dot{\mathrm{X}}_{1}= & r_{1} \mathrm{X}_{1}-r_{2} \mathrm{X}_{1} \mathrm{X}_{2}-r_{3} \mathrm{X}_{1} \mathrm{X}_{3}+r_{6} \\
& \left(\mathrm{Y}_{1}-\mathrm{X}_{1}\right)=\mathrm{F}_{1}\left(\mathrm{X}_{1}\right)+r_{6}\left(\mathrm{Y}_{1}-\mathrm{X}_{1}\right) \\
\dot{\mathrm{X}}_{2}= & r_{2} \mathrm{X}_{1} \mathrm{X}_{2}+r_{6} \mathrm{Y}_{2}-r_{4} \mathrm{X}_{2}-r_{6} \mathrm{X}_{2} \\
= & \mathrm{F}_{2}\left(\mathrm{X}_{2}\right)+r_{6}\left(\mathrm{Y}_{2}-\mathrm{X}_{2}\right) \\
\dot{\mathrm{X}}_{3}= & r_{3} \mathrm{X}_{1} \mathrm{X}_{3}+r_{6} \mathrm{Y}_{3}-r_{5} \mathrm{X}_{3}-r_{6} \mathrm{X}_{3} \\
= & \mathrm{F}_{3}\left(\mathrm{X}_{3}\right)+r_{6}\left(\mathrm{Y}_{3}-\mathrm{X}_{3}\right) \\
\dot{\mathrm{Y}}_{1}= & r_{1} \mathrm{Y}_{1}-r_{2} \mathrm{Y}_{1} \mathrm{Y}_{2}-r_{3} \mathrm{Y}_{1} \mathrm{Y}_{3}+r_{6}\left(\mathrm{X}_{1}-\mathrm{Y}_{1}\right) \\
= & \mathrm{G}_{1}\left(\mathrm{Y}_{1}\right)+r_{6}\left(\mathrm{X}_{1}-\mathrm{Y}_{1}\right) \\
\dot{\mathrm{Y}}_{2}= & r_{2} \mathrm{Y}_{1} \mathrm{Y}_{2}+r_{6} \mathrm{X}_{2}-r_{4} \mathrm{Y}_{2}- \\
& r_{6} \mathrm{Y}_{2}=\mathrm{G}_{2}\left(\mathrm{Y}_{2}\right)+r_{6}\left(\mathrm{X}_{2}-\mathrm{Y}_{2}\right) \\
\dot{\mathrm{Y}}_{3}= & r_{3} \mathrm{Y}_{1} \mathrm{Y}_{3}+r_{6} \mathrm{X}_{3}-r_{5} \mathrm{Y}_{3}- \\
& r_{6} \mathrm{Y}_{3}=\mathrm{G}_{3}\left(\mathrm{Y}_{3}\right)+r_{6}\left(\mathrm{X}_{3}-\mathrm{Y}_{3}\right)
\end{aligned}
$$

The error state was defined as $e_{i}=y_{i}-x_{i}(i=1,2,3)$, and the dynamics of error can be described as follows:

$$
\left\{\begin{array}{l}
\frac{\mathrm{d} e_{1}}{\mathrm{~d} t}=\mathrm{G}_{1}\left(\mathrm{Y}_{1}\right)-\mathrm{F}_{1}\left(\mathrm{X}_{1}\right)-2 r_{6} e_{1} \\
\frac{\mathrm{d} e_{2}}{\mathrm{~d} t}=\mathrm{G}_{2}\left(\mathrm{Y}_{2}\right)-\mathrm{F}_{2}\left(\mathrm{X}_{2}\right)-2 r_{6} e_{2} \\
\frac{\mathrm{d} e_{3}}{\mathrm{~d} t}=\mathrm{G}_{3}\left(\mathrm{Y}_{3}\right)-\mathrm{F}_{3}\left(\mathrm{X}_{3}\right)-2 r_{6} e_{3}
\end{array}\right.
$$




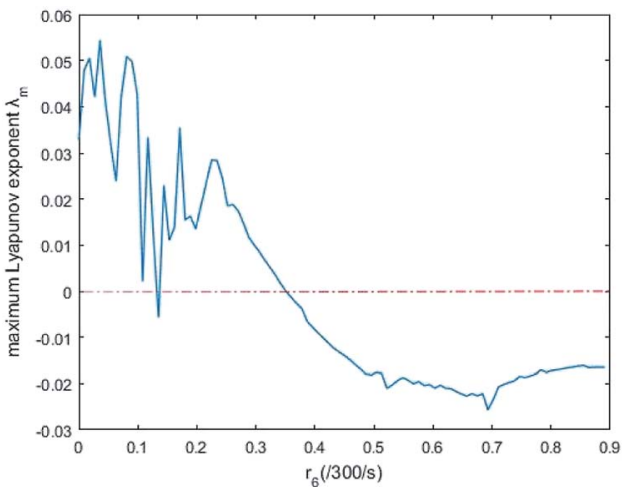

Fig. 9 The evolution of maximum Lyapunov exponent with chemical reaction rate $r_{6}$.

Table 1 Parameter Values of the Lotka-Volterra Oscillator

\begin{tabular}{llllll}
\hline \multicolumn{1}{l}{ Values } & & Values & Values \\
\hline$r_{1}$ & $5.5 / 300 \mathrm{~s}^{-1}$ & $q_{1}$ & $r_{1} C_{m}{ }^{-1}$ & $C_{m}$ & $2 \times 10^{-5} \mathrm{M}$ \\
$r_{2}$ & $10^{6} \mathrm{M} \mathrm{s}^{-1}$ & $q_{2}$ & $10^{5} \mathrm{M} \mathrm{s}^{-1}$ & $q_{m}$ & $10^{6} \mathrm{M} \mathrm{s}^{-1}$ \\
$r_{3}$ & $1.008 \times 10^{6} \mathrm{M} \mathrm{s}^{-1}$ & $q_{3}$ & $r_{2}$ & & \\
$r_{4}$ & $4 / 300 \mathrm{~s}^{-1}$ & $q_{4}$ & $10^{5} \mathrm{M} \mathrm{s}^{-1}$ & & \\
$r_{5}$ & $4 / 300 \mathrm{~s} \mathrm{~s}^{-1}$ & $q_{5}$ & $r_{3}$ & \\
$r_{6}$ & $0.8 / 300 \mathrm{~s} \mathrm{~s}^{-1}$ & $q_{6}$ & $10^{5} \mathrm{M} \mathrm{s}^{-1}$ & \\
& & $q_{7}$ & $r_{4} C_{m}{ }^{-1}$ & \\
& & $q_{8}$ & $r_{5} C_{m}{ }^{-1}$ & \\
& & $q_{9}$ & $2 \times 10^{5} \mathrm{M} \mathrm{s}^{-1}$ & \\
& & $q s$ & $r_{6}\left(q_{m}+q_{9}\right) /\left(q_{9} C_{m}\right)$ & \\
& & & &
\end{tabular}

In simulations, the two 3-variable Lotka-Volterra oscillator systems with different initial values, and the evolution of the maximum Lyapunov exponent of eqn (53) with the chemical reaction rate $r_{6}$ is given in Fig. 9. When the maximal Lyapunov exponent $\lambda_{m}$ is negative, the synchronization of the two 3-variable Lotka-Volterra oscillator systems can be obtained. ${ }^{30}$

CRNs (45) and (46) can be described by the abovementioned DNA reaction modules as follows:

$$
\begin{gathered}
\mathrm{X}_{1}+\mathrm{A}_{1}^{\prime} \stackrel{q_{1}}{\longrightarrow} \mathrm{T}_{1}^{\prime}+\mathrm{B}_{1}^{\prime} \\
\mathrm{T}_{1}^{\prime}+\mathrm{C}_{1}^{\prime} \stackrel{q_{m}}{\longrightarrow} 2 \mathrm{X}_{1}^{\prime}+\text { waste } \\
\mathrm{X}_{1}^{\prime}+\mathrm{P}_{1}^{\prime} \stackrel{q_{m}}{\longrightarrow} \mathrm{S}_{1}^{\prime} \\
\mathrm{S}_{1}^{\prime}+\mathrm{Sp}_{1}^{\prime} \stackrel{q_{m}}{\rightleftarrows} \mathrm{X}_{1}+\mathrm{Sq}_{1}^{\prime} \\
\mathrm{X}_{1}+\mathrm{A}_{1} \stackrel{q_{3}}{\rightleftarrows} \mathrm{T}_{1}+\mathrm{B}_{1} \\
\mathrm{X}_{2}+\mathrm{T}_{1} \stackrel{q_{m}}{\longrightarrow} \text { waste }+\mathrm{C}_{1} \\
\mathrm{C}_{1}+\mathrm{H}_{1} \stackrel{q_{m}}{\longrightarrow} \text { waste }+2 \mathrm{X}_{2}^{\prime} \\
\mathrm{X}_{2}^{\prime}+\mathrm{P}_{1} \stackrel{q_{m}}{\longrightarrow} \mathrm{S}_{1}
\end{gathered}
$$

$$
\begin{aligned}
& \mathrm{S}_{1}+\mathrm{Sp}_{1} \underset{q_{m}}{\stackrel{q_{4}}{\rightleftarrows}} \mathrm{X}_{2}+\mathrm{Sq}_{1} \\
& \mathrm{X}_{1}+\mathrm{A}_{2} \underset{q_{m}}{\stackrel{q_{5}}{\rightleftarrows}} \mathrm{T}_{2}+\mathrm{B}_{2} \\
& \mathrm{X}_{3}+\mathrm{T}_{2} \stackrel{q_{m}}{\longrightarrow} \text { waste }+\mathrm{C}_{2} \\
& \mathrm{C}_{2}+\mathrm{H}_{2} \stackrel{q_{m}}{\longrightarrow} \text { waste }+2 \mathrm{X}_{3}^{\prime} \\
& \mathbf{X}_{3}^{\prime}+\mathrm{P}_{2} \stackrel{q_{m}}{\longrightarrow} \mathbf{S}_{2} \\
& \mathrm{~S}_{2}+\mathrm{Sp}_{2} \underset{q_{m}}{\stackrel{q_{6}}{\rightleftarrows}} \mathrm{X}_{3}+\mathrm{Sq}_{2} \\
& \mathrm{X}_{2}+\mathrm{F}_{1} \stackrel{q_{7}}{\longrightarrow} \mathrm{E}_{1} \\
& \mathrm{X}_{3}+\mathrm{F}_{2} \stackrel{q_{8}}{\longrightarrow} \mathrm{E}_{2} \\
& \mathrm{Y}_{1}+\mathrm{A}_{3}^{\prime} \stackrel{q_{1}}{\longrightarrow} \mathrm{T}_{3}^{\prime}+\mathrm{B}_{3}^{\prime} \\
& \mathrm{T}_{3}^{\prime}+\mathrm{C}_{3}^{\prime} \stackrel{q_{m}}{\longrightarrow} 2 \mathrm{Y}_{1}^{\prime}+\text { waste } \\
& \mathrm{Y}_{1}^{\prime}+\mathrm{P}_{3}^{\prime} \stackrel{q_{m}}{\longrightarrow} \mathrm{S}_{3}^{\prime} \\
& \mathrm{S}_{3}^{\prime}+\mathrm{Sp}_{3}^{\prime} \underset{q_{2}}{\stackrel{q_{m}}{\rightleftarrows}} \mathrm{Y}_{1}+\mathrm{Sq}_{3}^{\prime} \\
& \mathrm{Y}_{1}+\mathrm{A}_{3} \underset{q_{m}}{\stackrel{q_{3}}{\rightleftarrows}} \mathrm{T}_{3}+\mathrm{B}_{3} \\
& \mathrm{Y}_{2}+\mathrm{T}_{3} \stackrel{q_{m}}{\longrightarrow} \text { waste }+\mathrm{C}_{3} \\
& \mathrm{C}_{3}+\mathrm{H}_{3} \stackrel{q_{m}}{\longrightarrow} \text { waste }+2 \mathrm{Y}_{2}^{\prime} \\
& \mathrm{Y}_{2}^{\prime}+\mathrm{P}_{3} \stackrel{q_{m}}{\longrightarrow} \mathrm{S}_{3} \\
& \mathrm{~S}_{3}+\mathrm{Sp}_{3} \underset{q_{m}}{\stackrel{q_{4}}{\rightleftarrows}} \mathrm{Y}_{2}+\mathrm{Sq}_{3} \\
& \mathrm{Y}_{1}+\mathrm{A}_{4} \underset{q_{m}}{\stackrel{q_{5}}{\rightleftarrows}} \mathrm{T}_{4}+\mathrm{B}_{4} \\
& \mathrm{Y}_{3}+\mathrm{T}_{4} \stackrel{q_{m}}{\longrightarrow} \text { waste }+\mathrm{C}_{4} \\
& \mathrm{C}_{4}+\mathrm{H}_{4} \stackrel{q_{m}}{\longrightarrow} \text { waste }+2 \mathrm{Y}_{3}^{\prime} \\
& \mathrm{Y}_{3}^{\prime}+\mathrm{P}_{4} \stackrel{q_{m}}{\longrightarrow} \mathrm{S}_{4} \\
& \mathrm{~S}_{4}+\mathrm{Sp}_{4} \underset{q_{m}}{\stackrel{q_{6}}{\rightleftarrows}} \mathrm{Y}_{3}+\mathrm{Sq}_{4} \\
& \mathrm{Y}_{2}+\mathrm{F}_{3} \stackrel{q_{7}}{\longrightarrow} \mathrm{E}_{3} \\
& \mathrm{Y}_{3}+\mathrm{F}_{4} \stackrel{q_{8}}{\longrightarrow} \mathrm{E}_{4} \\
& \mathrm{X}_{1}+\mathrm{U}_{1} \underset{q_{m}}{\stackrel{q_{9}}{\rightleftarrows}} \mathrm{V}_{1}+\mathrm{U}_{1}^{\prime}
\end{aligned}
$$



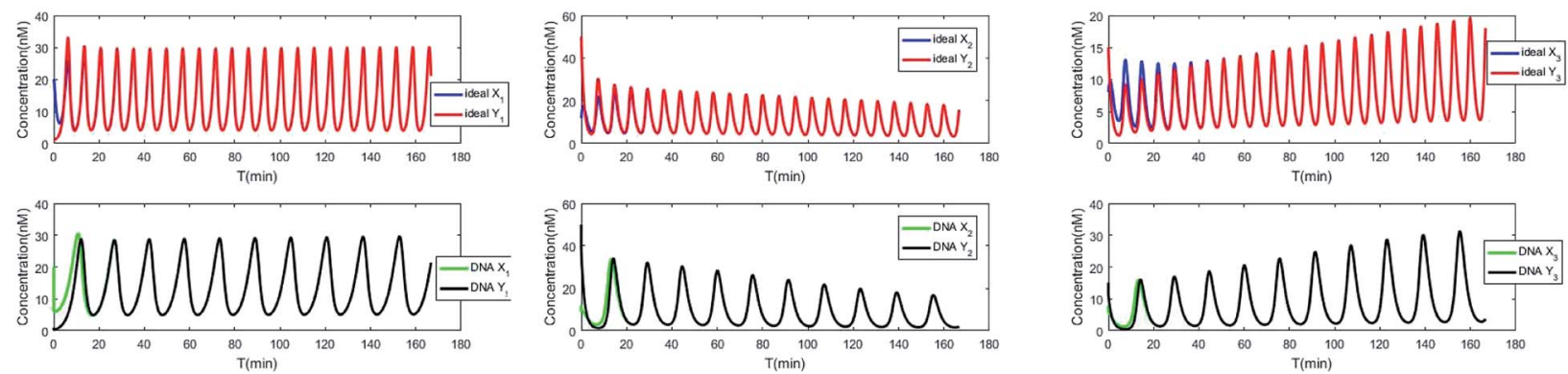

Fig. 10 Process of synchronization of two 3-variable Lotka-Volterra oscillator systems based on DNA and ideal CRNs.
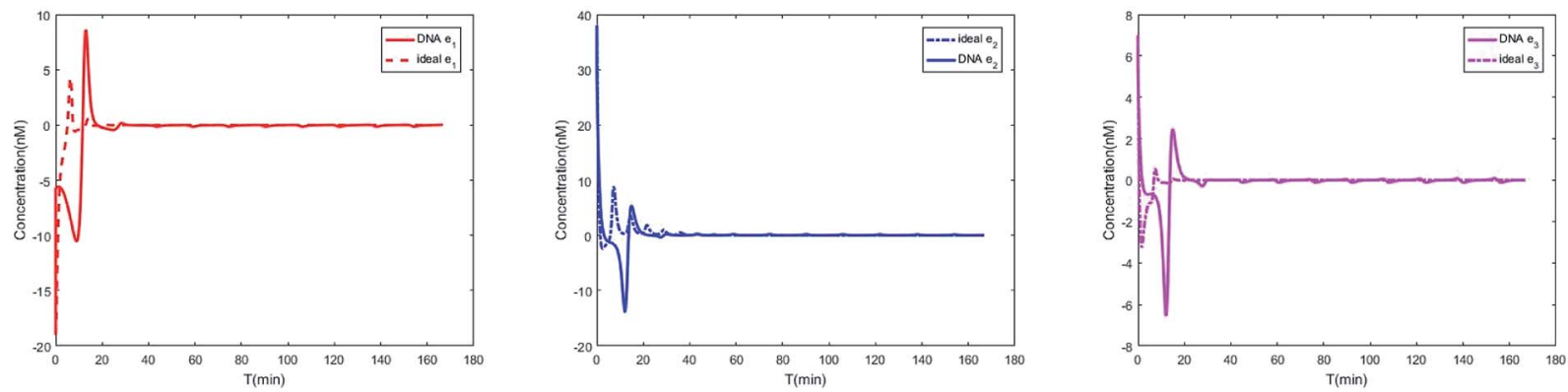

Fig. 11 Evolution of errors between two 3-variable Lotka-Volterra oscillator systems based on DNA and ideal CRNs.

$$
\begin{gathered}
\mathrm{U}_{2}+\mathrm{V}_{1} \stackrel{q s}{\longrightarrow} \mathrm{V}_{2}+\text { waste } \\
\mathrm{U}_{3}+\mathrm{V}_{2} \stackrel{q_{m}}{\longrightarrow} \mathrm{Y}_{1}+\text { waste } \\
\mathrm{X}_{2}+\mathrm{U}_{4} \underset{q_{m}}{\stackrel{q_{9}}{\longrightarrow}} \mathrm{V}_{3}+\mathrm{U}_{4}^{\prime} \\
\mathrm{U}_{5}+\mathrm{V}_{3} \stackrel{q s}{\longrightarrow} \mathrm{V}_{4}+\text { waste } \\
\mathrm{U}_{6}+\mathrm{V}_{4} \stackrel{q_{m}}{\longrightarrow} \mathrm{Y}_{2}+\text { waste } \\
\mathrm{X}_{3}+\mathrm{U}_{7} \stackrel{q_{9}}{\rightleftarrows} \mathrm{V}_{5}+\mathrm{U}_{7}^{\prime} \\
\mathrm{U}_{8}+\mathrm{V}_{5} \stackrel{q_{m}}{\longrightarrow} \mathrm{V}_{6}+\text { waste } \\
\mathrm{U}_{9}+\mathrm{V}_{6} \stackrel{q_{m}}{\longrightarrow} \mathrm{Y}_{3}+\text { waste }
\end{gathered}
$$

Visual DSD software can be used to realize the approximations of the CRNs (45) and (46)..$^{22}$ The DSD implementation of the catalysis reactions (54) and (59) are shown in Fig. 3. The DSD implementation of the catalysis reactions (55), (56), (60) and (61) are shown in Fig. 4. The reactions (57), (58), (62) and (63) are degradation reactions. The DSD implementation of reactions (57), (58), (62) and (63) are shown in Fig. 5. Reactions (64)(66) are used as the synchronization module. The DSD implementation of reactions (64)-(66) are shown in Fig. 6.

\section{Simulation results}

The parameters of the 3-variable Lotka-Volterra oscillator are given in Table 1 , and $\left[\mathrm{X}_{1}\right]_{0},\left[\mathrm{X}_{2}\right]_{0},\left[\mathrm{X}_{3}\right]_{0},\left[\mathrm{Y}_{1}\right]_{0},\left[\mathrm{Y}_{2}\right]_{0}$ and $\left[\mathrm{Y}_{3}\right]_{0}$ represent the initial values of species $\mathrm{X}_{1}, \mathrm{X}_{2}, \mathrm{X}_{3}, \mathrm{Y}_{1}, \mathrm{Y}_{2}$ and $\mathrm{Y}_{3}$, respectively. $\left[\mathrm{X}_{1}\right]_{0}=20 \mathrm{nM},\left[\mathrm{X}_{2}\right]_{0}=12 \mathrm{nM},\left[\mathrm{X}_{3}\right]_{0}=8 \mathrm{nM},\left[\mathrm{Y}_{1}\right]_{0}=$ $1 \mathrm{nM},\left[\mathrm{Y}_{2}\right]_{0}=50 \mathrm{nM}$, and $\left[\mathrm{Y}_{3}\right]_{0}=15 \mathrm{nM}$, where the values of chemical reaction rates $r_{i},(i=1, \cdots, 5)$ are referenced ${ }^{\mathbf{1}}$.

The evolution of the 3 -variable Lotka-Volterra oscillator based on ideal CRNs and the 3-variable Lotka-Volterra oscillator based on DNA CRNs are shown in Fig. 7 and 8. When the three coupling terms are added to the system, the evolution of the 3-variable Lotka-Volterra oscillator based on DNA CRNs and the 3-variable Lotka-Volterra oscillator based on ideal CRNs are given in Fig. 9. According to Fig. 10, it can be found that the error between $\mathrm{Y}_{i}$ and $\mathrm{X}_{i}(i=1,2,3)$ approaches zero, which indicates that synchronization among $\mathrm{X}_{i}$ and $\mathrm{Y}_{i}$ with different initial concentrations is realized. It is clear that errors between $\mathrm{X}_{i}$ and $\mathrm{Y}_{i}$ in the ideal CRNs approach zero, which is similar to errors in DNA CRNs, as shown in Fig. 10 and 11.

In CRNs, luminous intensity relates to the concentration of DNA strands. We can observe the process of synchronization of the two 3-variable Lotka-Volterra oscillator systems through luminous intensity. The luminous intensity of $\mathrm{X}_{i}$ and $\mathrm{Y}_{i}$ are different without adding coupling terms to the systems. The luminous intensity of $\mathrm{X}_{i}$ and $\mathrm{Y}_{i}$ reach unanimity when there is synchronization among $\mathrm{X}_{i}$ and $\mathrm{Y}_{i}$. 


\section{Conclusion}

We proposed a 3-variable Lotka-Volterra oscillator system as an example and realized synchronization of two 3-variable LotkaVolterra oscillator systems with different initial concentrations. For more convenient observation and more accurate detection of synchronization, DNA strands were designed with fluorophores and quenchers. We demonstrated the contributions of fluorophores and quenchers using the CRNs modules, and analyzed the differences between DNA CRNs and ideal formal CRNs. We used Visual DSD software as a design tool for the DNA strands and CRN language to simulate the synchronization of two 3-variable Lotka-Volterra oscillator systems, one each in DNA CRNs and ideal CRNs. Numerical simulation demonstrates that the method of synchronization in this article is effective for ideal CRNs as well as DSD implementation CRNs.

\section{Conflicts of interest}

There are no conflicts to declare.

\section{Acknowledgements}

This study was supported by the National Natural Science Foundation of China (No. 61425002, 61751203, 61772100) and by the Program for Changjiang Scholars and Innovative Research Team in University (No. IRT_15R07). We thank LetPub (http:/www.letpub.com) for its linguistic assistance during the preparation of this manuscript.

\section{References}

1 D. Soloveichik, G. Seelig and E. Winfree, DNA as a universal substrate for chemical kinetics, Proc. Natl. Acad. Sci. U. S. A., 2010, 107, 5393-5398.

2 R. Sawlekar, F. Montefusco, V. V. Kulkarni and D. G. Bates, Implementing nonlinear feedback controllers using DNA strand displacement reactions, IEEE Transactions on Nanobioscience, 2016, 15, 443-454.

3 X. Olson, S. Kotani, B. Yurke, E. Graugnard and W. Hughes, Kinetics of DNA Strand Displacement Systems with Locked Nucleic Acids, J. Phys. Chem. B, 2017, 121, 2594-2602.

4 W. Li, F. Zhang, H. Yan and Y. Liu, DNA based arithmetic function: a half adder based on DNA strand displacement, Nanoscale, 2016, 8, 3775-3784.

5 J. W. Sun, X. Li, G. Z. Cui and Y. F. Wang, One-bit half adderhalf subtractor logical operation based on the DNA strand displacement, J. Nanoelectron. Optoelectron., 2017, 12, 375380.

6 M. R. Lakin and D. Stefanovic, Supervised Learning in Adaptive DNA Strand Displacement Networks, ACS Synth. Biol., 2016, 5, 885-897.

7 T. Song, S. Garg, R. Mokhtar, H. Bui and J. Reif, Analog Computation by DNA Strand Displacement Circuits, ACS Synth. Biol., 2016, 5, 898-912.

8 G. Cui, J. Zhang, Y. Cui, T. Zhao and Y. Wang, DNA stranddisplacement digital logic circuit with fluorescence resonance energy transfer detection, J. Comput. Theor. Nanosci., 2015, 12, 2095-2100.

9 M. Song, Y. C. Wang, M. H. Li and Y. F. Dong, Metalmediated logic computing model with DNA strand displacement, J. Comput. Theor. Nanosci., 2010, 12, 23182321.

10 L. Qian and E. Winfree, Scaling Up Digital Circuit Computation with DNA Strand Displacement Cascades, Science, 2011, 332, 1196-1201.

11 L. Qian, E. Winfree and J. Bruck, Neural network computation with DNA strand displacement cascades, Nature, 2011, 475, 368-372.

12 A. J. Thubagere, C. Thachuk, J. Berleant, R. Johnson, D. Ardelean, K. M. Cherry and L. L. Qian, Compiler-aided systematic construction of large-scale DNA strand displacement circuits using unpurified components, Nat. Commun., 2017, 8.

13 G. Z. Cui, J. Y. Zhang, Y. H. Cui, T. T. Zhao and Y. F. Wang, DNA strand-displacement digital logic circuit with fluorescence resonance energy transfer detection, $J$. Comput. Theor. Nanosci., 2015, 12, 2095-2100.

14 Z. Zhang, T. W. Fan and I. M. Hsing, Integrating DNA strand displacement circuitry to the nonlinear hybridization chain reaction, Nanoscale, 2017, 9, 2748-2754.

15 M. J. Zhang, R. M. Li and L. S. Ling, Homogenous assay for protein detection based on proximity DNA hybridization and isothermal circular strand displacement amplification reaction, Anal. Bioanal. Chem., 2017, 409, 4079-4085.

16 K. Miyakawa, T. Okano and S. Yamazaki, Cluster synchronization in a chemical oscillator network with adaptive coupling, J. Phys. Soc. Jpn, 2013, 82.

17 A. Alofi, F. L. Ren, A. Al-Mazrooei, A. Elaiw and J. D. Cao, Power-rate synchronization of coupled genetic oscillators with unbounded time-varying delay, Cogn. Neurodyn., 2015, 9, 549-559.

18 J. F. Totz, R. Snari, D. Yengi, M. R. Tinsley, H. Engel and K. Showalter, Phase-lag synchronization in networks of coupled chemical oscillators, Phys. Rev. E, 2015, 92.

19 Z. Nie, P. F. Wang, C. Tian and C. D. Mao, Synchronization of two assembly processes to build responsive DNA nanostructures, Angew. Chem., Int. Ed., 2014, 53, 8402-8405.

20 A. Apraiz, J. Mitxelena and A. Zubiaga, Studying cell cycleregulated gene expression by two complementary cell synchronization protocols, J. Vis. Exp, 2017, 124.

21 D. J. Ferullo, D. L. Cooper, H. R. Moore and S. T. Lovett, Cell cycle synchronization of Escherichia coli using the stringent response, with fluorescence labeling assays for DNA content and replication, Methods, 2009, 48, 8-13.

22 M. R. Lakin, S. Youssef, F. Polo, S. Emmott and A. Phillips, Visual DSD: A design and analysis tool for DNA strand displacement systems, Bioinformatics, 2011, 27, 3211-3213.

23 D. Y. Zhang and E. Winfree, Control of DNA Strand displacement kinetics using toehold exchange, J. Am. Chem. Soc., 2009, 131, 17303-17314.

24 K. Sakamoto, H. Gouzu, K. Komiya, D. Kiga, S. Yokoyama, T. Yokomori and M. Hagiya, Molecular computation by DNA hairpin formation, Science, 2000, 288, 1223-1226. 
25 J. Xie, Q. Mao, W. L. Tai Phillip, R. He, J. Z. Ai, Q. Su, Y. Zhu, H. Ma, J. Li, S. F. Gong, D. Wang, Z. Gao, M. X. Li, L. Zhong, H. Zhou and G. P. Gao, Short DNA Hairpins Compromise Recombinant Adeno-Associated Virus Genome Homogeneity, Mol. Ther., 2017.

26 C. B. Ma, H. S. Liu, K. F. Wu, M. J. Chen, L. Y. Zheng and J. Wang, An exonuclease I-based quencher-free fluorescent method using DNA hairpin probes for rapid detection of microRNA, Sensors, 2010, 17.
27 H. Matsuda, N. Ogita, A. Sasaki and K. Sato, StatisticalMechanics Of Population - The Lattice Lotka-Volterra Model, Prog. Theor. Phys., 1992, 88, 1035-1049.

28 Y. K. Li and Y. Kuang, Periodic solutions of periodic delay Lotka-Volterra equations and systems, J. Math. Anal. Appl., 2001, 255, 260-280.

29 S. R. Dunbar, Traveling Wave Solutions of Diffusive LotkaVolterra equations, Journal of Mathematical Biology, 1983, 17, 11-32.

30 P. Badola, S. S. Tambe and B. D. Kulkarni, Driving systems with chaotic signals, Phys. Rev. A, 1992, 46, 6735-6737. 